\title{
REPORT OF THE EXECUTIVE COMMITTEE
}

1985-1988

\section{EXFCUTIVE COMMITTEE}

$1985-1988$

\section{President:}

Prof. J. Sahade

\section{Vice-Presidents:}

Dr. A.H. Batten

Prof. R. Kippenhahn

Prof. R.P. Kraft

Prof. P.O. Lindblad

Prof. M. Peimbert

Prof. Ya. S. Yatskiv

\section{General Secretary:}

Dr. J.-P. Swings

Assistant General Secretary:

Dr. D. McNally
C.C. No. 677, Observatorio Astronomico, Universidad Nacional de La Plata, 1900 La Plata (Bs. As.), Argentina

Herzberg Institute of Astrophysics, Dominion Astrophysical Observatory, 5071 West Saanich Road, Victoria BC, V8X 4M6, Canada

MPI für Physik \& Astrophysik,

Karl-Schwarzschild-Strasse 1, D-8046 Garching bei München, Germany, FR

Lick Observatory, University of California, Santa Cruz, CA 95064, USA

Stockholm Observatory, 5613300 Saltsjöbaden, Sweden

Instituto de Astronomia, Apartado Postal 70264, Mexico 04510 DF, Mexico

Main Astronomical Observatory, Ukrainian Academy of Sciences, SU-252127 Kiev, USSR

Institut d'Astrophysique, 5, avenue de Cointe, B-4200 Cointe-Ougrée, Belgium

University of London Observatory, Mill Hill Park, London NW7 2QS, UK

\section{Advisers:}

Emeritus Prof.

R. Hanbury Brown

Dr. R.W. West
37 Beatty Street, Balgowlah, NSW 2093, Australia

European South Observatory, Karl-Schwarzschild Strasse 2, D-8046, Garching bei München, Germany, FR 


\section{Introduction}

The present report covers the period from the end of the XIXth General Assembly up to mid 1988.

The report by the General Secretary at the XXth General Assembly for the period lst January-31 July, 1988 is to be found pp. 26-28.

A summarized financial report of the Union audited accounts for the calendar years 1985,1986 \& 1987 and a brief resume of the Union's accounts for 1988 are also included.

\section{Administration}

\section{Executive Committee Meetings}

The Executive Committee held the following meetings:

$\begin{array}{ll}\text { 53rd Meeting: } & \text { Delhi, India, November 17,18 \& 26, } 1985 \\ \text { 54th Meeting: } & \text { Delhi, India, November 28, 1986 } \\ \text { 55th Meeting: } & \text { Liège, Belgium, September 19-22, 1986 } \\ \text { 56th Meeting: } & \text { Santa Cruz, USA, September 9-12, } 1987\end{array}$

The 53rd Meeting was chaired by Professor R. Hanbury Brown while the 54th was chaired by the newly elected President, Professor J. Sahade; the new Members of the Executive Committee were all present, as well as the two advisers. The 55th and 56th Meetings were also chaired by Professor J. Sahade.

\section{Officers' Meetings}

The President, the General Secretary and the Assistant General Secretary met as follows:
November 16, 1985
Delhi, India
May 14, 1986
Paris, France
September 18, 1986
Liège, Belgium
March 11-12, 1987
Paris, France
September 8, 1987
Santa Cruz, USA
November 6, 1987
Paris, France
March 10-11, 1988
Baltimore, USA

\section{IAU Secretariat}

The secretariat is in the process of moving to the following address:

$$
\begin{gathered}
\text { 98bis, boulevard Arago } \\
\text { F-75014 - PARIS, France }
\end{gathered}
$$

The phone and telex numbers remain unchanged.

\section{IAU Staff}

Miss D. Lours and Mrs. B. Manning left the secretariat on April 27, and June 25, 1987, respectively. They have been replaced by Mrs. Monique Orine, administrative assistant, and Mrs. Huguette Gigan, part-time bilingual secretary, as of September 1, and October 15, 1987, respectively. 


\section{Adhering Countries}

Nigerian membership of IAU was ratified by the XIXth General Assembly (motion adopted unanimously, see Transactions XIXB, p. 54).

\section{Members of the IAU}

The XIXth General Assembly welcomed 935 new members: the total number of IAU members thus became 6027 , on 28 November 1985 . The number, as of June 1988, is 5940 .

\section{Consultants to IAU Commissions}

The 40 IAU Commissions had a total of approximately 200 consultants.

\section{Commissions of the IAU}

The name of Commission 51 has become "Bioastronomy: Search for Extraterrestrial Life", as of the end of the XIXth General Assembly.

Commission Reports, covering the period July 1, 1984, to June 30, 1987 have been published (Reports on Astronomy; IAU Transactions XXA, 708 pp.).

An updated list of the IAU Working Groups, belonging to one or more Commissions, has been published (cf. IB 59, pp. 11-13).

A few specific points about some Commission activities, especially those providing services to the astronomical community, are listed below:

\section{Commission 5}

Work has continued on the new IAU Style Manual, largely due to the active role of G. Wilkins (cf. IB 60, p. 26): the Manual is expected to be presented at the $X X$ th General Assembly. Contacts have also been made with editors of the main astronomical journals to atternpt to coordinate the rules of publication.

\section{Commission 6}

The IAU Central Bureau for Astronomical Telegrams (Director: B.G. Marsden) issued the following number of circulars and "telegram books" respectively in 1985 , 1986, and 1987: 132, 35; 135, 41; 230, 55; i.e. a total of 497 circulars and of 131 "telegram books".

\section{Commissions 19 and 31}

The new International Earth Rotation Service (IERS) established in 1987 by the IAU and the IUGG, has become operational on January 1,1988 (cf. IB 59, p. 15).

\section{Commission 20}

Together with Commission 6 and the IAU Working Group on Planetary System Nomenclature (WGPSN), procedures were established for assigning names and designations to various classes of newly discovered bodies in the solar system. The IAU Minor Planet Center (Director: B.G. Marsden) issued 3330 MPCs and numbered no less than 554 new minor planets during 1985-1987.

\section{Commission 22}

The IAU Meteor Data Center, created in Lund, Sweden (director: B.A. Lindblad) has computed and archived an impressive number of orbits. A report by B.A. Lindblad has been published for the period 1985-1987 (cf. IB 59, p. 17 \& IB 60, p. 27). 


\section{Commission 38}

Under the guidance of its President, E.A. Müller, this Commission continued to give assistance to (young) astronomers under the rules published in IB 55, pp. 25-27. The names of the 23 grant recipients for the period February 1985-November 1987 have been published in IB 59, pp. 18-19.

\section{Commission 46: Visiting Lecturers' Programmes (VLP)}

a. VLP in Lima (Peru): see IB 56, p. 14; 57, p. $16 \& 58$, p. 16. A limited extension of this VLP will start shortly.

b. VLP in Asuncion (Paraguay): a description appeared in IB 58, pp. 16-17 \& 60, p. 27. The present contract is only for one year, starting in 1988. The possibility of the extension of the contract will be examined by the next Executive Committee.

\section{Commission 46}

New rules concerning the membership and activities of Commission 46 are under preparation. Two IAU-UNESCO International Schools for Young Astronomers were succesfully held in Beijing (10-30 August 1986) and Porto (15-27 September 1986).

\section{Scientific meetings}

\section{Symposia (22)}

114 Relativity in Celestial Mechanics and Astrometry - High Precision Dynamical Theories and Observational Verifications

Leningrad, USSR, May 28-31, 1985

115 Star Forming Regions

Tokyo, Japan, November 11-15, 1985

116 Luminous Stars and Associations in Galaxies

Porto Heli, Greece, May 26-31, 1985

117 Dark Matter in the Universe

Princeton, USA, June 24-28, 1985

118 Instrumentation and Research Programs for Sinall Telescopes

Christchurch, New Zealand, December 2-6, 1985

119 Quasars

Bangalore, India, December 2-6, 1985

120 Astrochernistry

Goa, India, December 3-7, 1985

121 Observational Evidence of Activity in Galaxies

Byurakan, Armenia, USSR, June 3-7, 1986

122 Circumstellar Matter

Heidelberg, Germany, FR, June 23-27, 1986

123 Advances in Helio- and Asteroseismology

Aarhus, Denmark, July 7-11, 1986

124 Observational Cosmology

Shanghai, China, PR, August 25-29, 1986 
125 The Origin and Evolution of Neutron Stars Nanjing, China, PR, May 26-29, 1986

126 Globular Cluster Systems in Galaxies Cambridge, MA, USA, August 25-29, 1986

127 Structure and Dynamics of Elliptical Galaxies Princeton, USA, May 28-31, 1986

128 Earth's Rotation and Reference Frames for Geodesy and Geodynamics Washington, USA, October 20-24, 1986

129 The Impact of VLBI on Astrophysics, Astrometry and Geophysics Cambridge, MA, USA, May 31 - June 3, 1987

130 Evolution of Large Scale Structures in the Universe Balatonfured, Hungary, June 15-20, 1987

131 Planetary Nebulae Mexico City, Mexico, October 5-9, 1987

132 The Impact of Very High S/N Spectroscopy on Stellar Physics Paris, France, June 29-July 3, 1987

133 Mapping the Sky - Past Heritage and Future Directions Paris, France, June 1-5, 1987

135 Interstellar Dust Mountain View, CA, USA, July 26-30, 1988

136 The Galactic Center Los Angeles, CA, USA, July 25-29, 1988

\section{Colloquia (21)}

87 Hydrogen Deficient Stars and Related Objects Mysore, India, November 10-15, 1985

88 Stellar Radial Velocities Schenectady, NY, USA, October 24-27, 1984

89 Radiation Hydrodynamics in Stars and Compact Objects Copenhagen, Denmark, June 11-20, 1985

90 Upper Main Sequence Stars with Anomalous Abundances Nauchny, Crimea, May 14-17, 1985

91 History of Oriental Astronomy New Delhi, India, November 14-17, 1985

92 Physics of Be Stars Boulder, CO, USA, August 18-22, 1986

93 Cataclysmic Variables Bamberg, Germany, FR, June 16-20, 1986 
94 Physics of Formation of Fell Lines Outside LTE Capri, Italy, July 4-8, 1986

95 Second Conference on Faint Blue Stars Tucson, AZ, USA, May 31 - June 3, 1987

96 The Few Body Problem

Turku, Finland, June 14-19, 1987

97 Wide Components in Double and Multiple Stars: Prablems of Observation and Interpretation Brussels, Belgium, June 8-13, 1987

98 The Contribution of Amateur Astronomers to Astronomy Paris, France, June 20-24, 1987

99 Bioastronomy - The Next Steps Lake Balaton, Hungary, June 22-27, 1987

100 Fundamentals of Astrometry Belgrade, Yugoslavia, September 8-11, 1987

101 Interaction of Supernova Remnants with the Interstellar Medium Penticton, BC, Canada, June 9-12, 1987

102 UV and X-Ray Spectroscopy of Astrophysical and Laboratory Plasmas Beaulieu-sur-Mer, France, September 9-11, 1987

103 The Symbiotic Phenomenon Torun, Poland, 18-21 August, 1987

105 The Teaching of Astronomy Williamstown, NY, USA, July 27-30, 1988

106 Evolution of Peculiar Red Giant Stars Bloomington, IN, USA, July 27-29, 1988

109 Applications of Computer Technology to Dynamical Astronomy Gaithersburg, MD, USA, July 27-29, 1988

110 Library and Information Services in Astronomy Washington, DC, USA, July 28-30, August 1, 1988

\section{Co-sponsored Meetings}

CNES/IAU Meeting on "Comparative Study of Magnetospheric Systems" La Londe des Maures, France September 9-14, 1985

IAG/IAU/COSPAR Symposium on "Figure and Dynamics of the Earth, Moon, and Planets"

Praha, Czechoslovakia, September 15-20, 1986

IAU/ESLAB Symposium on "Exploration of Halley's Comet" Heidelberg, Germany, FR, October 27-31, 1986

COSPAR/IAU Symposium on "UV Space Astronomy: Physical Processes in the Local Interstellar Medium" Toulouse, France, June 30 - July 12, 1986 
COSPAR/IAU Symposium on "Latest Results on Venus and Uranus Missions" Toulouse, France, June 30-July 12, 1986

COSPAR/IAU Symposium on "Solar and Stellar Activity"

Toulouse, France, June 30-July 12, 1986

COSPAR/IAU Symposium on "Comets Halley and Giacobini-Zinner"

Toulouse, France, June 30-July 12, 1986

SCOSTEP/IAU 6th International Symposium on "Solar-Terrestrial Physics" Toulouse, France, June 30-July 5, 1986

SCOSTEP/IAU Symposium "Synopsis of the Solar Maximum Analysis" Toulouse, France, July 2-5, 1986

Symposium on "Image Detection and Quality", with Commission Internationale d'Optique, Paris, July 16-18, 1986

COSPAR/IAU Symposium on "Physics of Compact Objects: Theory versus Observations"

Sofia, Bulgaria, July 13-19, 1987

COSPAR/IAU/IUGG/IUPAP/SCOSTEP/URSI/WMO Symposium on "The Middle Atmosphere after MAP"

Espoo, Finland, 19-23 July, 1988

COSPAR/IAU/SCOSTEP Symposium on "International Heliospheric Study" Espoo, Finland, 20-23 July, 1988

COSPAR/IAU/IUPAP Symposium on "Cosmic Ray Studies in Space"

Espoo, Finland, 25-26 July, 1988

COSPAR/IAGA/IAU Symposium on "Studies of Cometary Environments: Modelling and Space Missions"

Espoo, Finland, 25-26 July, 1988

COSPAR/IAU/IUPAP Symposium on "Relativistic Gravitation"

Espoo, Finland, 18-19 July, 1988

COSPAR/IAA/IAU/IUGG/IUGS Symposium on "The Outer Planets: Current Knowledge, Future Prospects"

Espoo, Finland, 19-20 July, 1988

COSPAR/IAA/IAU Symposium on "Advances and Perspectives in X-Ray and Gamma-Ray Astronomy"

Espoo, Finland, 19-20 July, 1988

COSPAR/IAA/IAU/IUGG/IUGS Symposium on "Reappraisal of Moon and Mars/Phobos/Deimos: Preparation for Renewed Exploration"

Espoo, Finland, 21-22 July, 1988

COSPAR/IAA/IAU Symposium on "Magnetic Energy Conversion in Astrophysical and Laboratory Plasmas"

Espoo, Finland, 21-23 July, 1988

COSPAR/IAU Symposium on "Space Observations of Solar Variability" Espoo, Finland, 27-28 July, 1988 
COSPAR/IAU Workshop on "Future Planetary Missions"

Toulouse, France, June 30 -July 12, 1986

COSPAR/IAU Workshop on "Contamination of Environment of Space Shuttle for Astronomical Observations,

Toulouse, France, June 30 -July 12, 1986

COSPAR/IAU Workshop on "Chemical Evolution of Outer Planets, Satellites, and Small Bodies"

Toulouse, France, June 30 - July 12, 1986

COSPAR/IAA/IAU/IUGG/IUGS Workshop on "Future Planetary Missions"

Espoo, Finland, 20 July 1988

COSPAR/IAGA/IAU Workshop on "The Middle and Upper Atmosphere of Venus" Espoo, Finland, 25-27 July, 1988

COSPAR/IAU/SCOSTEP Workshop on "Scientific Planning for the Solar Maximum and Beyond"

Espoo, Finland, 25-27 July, 1988

COSPAR/IAU/IUGG Workshop on "Origin and Evolution of Planetary and Satellite Systems"

Espoo, Finland, 29-30 July, 1988

\section{Regional Meetings (4)}

Ninth European Regional Astronomy Meeting on "Activity in Stars and Galaxies" (with EPS)

Leicester, UK, September 2-5, 1986

Fifth Latin-American Regional Astronomy Meeting, Merida, Yucatan, Mexico,

October 6-10, 1986

Tenth European Regional Astronomy Meeting (with EPS),

Praha, Czechoslovakia, August 24-29, 1987

Fourth Asian-Pacific Regional Astronomy Meeting (with EPS), Beijing, China, PR, October 5-9, 1987

\section{IAU/UNESCO Young Astronomers' Schools (2)}

XIVth IAU-UNESCO International School for Young Astronomers Beijing, China, PR, 10-30 August, 1986

XVth IAU-UNESCO International School for Young Astronomers Porto, Portugal, 8-20 September 1986 
XIXth General Assembly, New Delhi, India, 19-28 November, 1985

IAU Transactions, Volume XIXB (1986), contain a report of the Proceedings of the General Assembly of the Union, including the resolutions passed at the Assembly. It also contains the reports of Commission meetings during the period of the General Assembly.

\section{Publications}

\section{Publisher}

In November 1984, the contract with D. Reidel Publishing Co. was renewed for a six-year period, from 1985-1991. The contract was continued when Reidel became a part of Kluwer Academic Publishers.

\section{Sales}

Number of copies sold (hard, soft) by D. Reidel Publishing Company in the period 1985-1987:

\section{Transactions:}

XIIIA (2), XIIIB (2), XIVA (2), XIVB (2), XVA (1), XVB (5), XVIA (3), XVIB (5), XVIIA part 1 (7), XVIIA part 2 (6), XVIIA part 3 (7), XVIIB (13), XVIIIA (30), XVIIIB (40), XIXA (431), XIXB (404).

\section{Highlights:}

I (10), II (13), III (17), IV I (8, 9), IV $2(8,9)$, V $(21,8)$, VI $(20,36)$, VII $(198,208)$.

\section{Symposia Proceedings:}

$32(20), 33(1), 34(4), 35(4), 37(4), 38(20), 39(8), 40(9), 43(18), 44(14), 45(32)$, $46(5), 47(8), 48(25), 49(4,22), 50(15,16), 51(5,20), 52(3,15), 53(2,9), 54(14$, 1), $55(6,16), 56(3,11), 57(4,11), 58(6,9), 59(12,23), 60(8,8), 61(9,17), 62(5$, $25), 63(22,0), 64(6,22), 65(6,3), 66(12,29), 67(52,22), 68(5,2), 69(4,24)$, $70(5,14), 71(13,14), 72(9,12), 73(12,20), 74(6,32), 75(15,54), 76(15,7)$, $77(10,34), 78(12,9), 79(15,30), 80(28,8), 81(7,40), 82(12,24), 83(14,33)$, $84(22,4), 85(8,19), 86(14,13), 87(21,11), 88(9,17), 89(9,14), 90(19,7), 91(18$, 9), $92(22,10), 93(14,14), 94(11,25), 95(18,7), 96(25,16), 97(21,13), 98(5,8)$, $99(12,18), 100(28,37), 101(38,26), 102(33,41), 103(28,34), 104(49,50), 105(58$, 107), $106(405,352), 107(276,197), 108(69,60), 109(322,208), 110(34,93)$, $111(373,253), 112(446,438), 113(373,287), 114(364,195), 115(302,213)$, $116(306,112), 117(290,273), 118(309,217), 119(331,311), 120(306,115)$.

\section{Information Bulletin}

Six issues of the Information Bulletin ( $n^{0} 55$ through 60) have been sent, free of charge, to IAU Members, consultants, scientific institutions, and selected international organizations. Each print-run was 7500 copies. 


\section{Relations to other organisations}

IAU was represented by the General Secretary at the following meetings of the International Council of Scientific Unions (ICSU): 20th meeting of the General Committee (München, Germany, FR, 1985), 21st General Assembly and 21st/22nd meetings of the General Committee (Bern, Switzerland, 1986) and 23rd meeting of the General Committee (Rome, Italy, 1987). The highlights concern future programmes such as the International Space Year (1992), and the large International Geosphere-Biosphere Programme (IGBP).

IAU was also represented at meetings of the ICSU Committee for Space Research (COSPAR): XXVIth Plenary meeting of COSPAR (Toulouse, France, 1986): J.-P. Swings and R. Wilson; XXVIIth Plenaary meeting of COSPAR (Espoo, Finland, 1988): J.-P. Swings.

The following IAU Representatives to other ICSU and international bodies were active during the period 1985-1988: it is to be noted that one minor change occurred: the present IAU representative to IAF (International Astronautical Federation) is Dr. Y. Kondo, President, IAU Commission 44:

\section{Organisation}

ICSU International Council of Scientific Unions General Committee

$\mathrm{BIH}(*) \quad$ Bureau International de l'Heure

CCDS Consultative Committee

for the Definition of the Second

Working Group on the Temps Atornique

International

CCIR International Radio Consultative Committee

Study Group 2

Study Group 7

CODATA Committee for Data for Science \& Technology

COSPAR Committee on Space Research

COSTED Committee on Science \& Technology

in Developing Countries

CTS Committee on the Teaching of Science

EPS European Physical Society

Conference Committee

FAGS Federation of Astronomical

$\&$ Geophysical Services

IAF

International Astronautical Federation

\section{Representative 1985-1988}

R.M. West (until Sept. 86) J.-P. Swings (after)

P. Pâquet

G. Winkler

J. Benavente

G. Winkler

J. Whiteoak

A.R. Thompson

J. Pilkington

G. Westerhout

J.-P. Swings

J.-P. Swings

L. Gouguenheim

D. McNally

J. Kovalevsky

E. Tandberg-Hanssen

M. Papagiannis/

Y. Kondo 


\begin{tabular}{|c|c|c|}
\hline $\operatorname{ICSTI}(* *)$ & $\begin{array}{l}\text { International Council for Scientific } \\
\& \text { Technical Information }\end{array}$ & G. Wilkins \\
\hline $\operatorname{IPMS}(*)$ & International Polar Motion Service & Ye Shu-Hua \\
\hline IUCAF & $\begin{array}{l}\text { Inter-Union Commission on Frequency } \\
\text { Allocation for Radio Astronomy } \\
\text { \& Space Science }\end{array}$ & $\begin{array}{l}\text { R. Schilizzi } \\
\text { G. Swarup }\end{array}$ \\
\hline IUPAP & $\begin{array}{l}\text { International Union of Pure } \\
\text { \& Applied Physics }\end{array}$ & V. Trimble \\
\hline IUWDS & International Ursigram \& World Day Service & H. Coffey \\
\hline QBSA & Quarterly Bulletin on Solar Activity & E. Hiei \\
\hline SCOPE & $\begin{array}{l}\text { Scientific Committee on Problems } \\
\text { of Environment }\end{array}$ & R. Cayrel \\
\hline SCOSTEP & $\begin{array}{l}\text { Scientific Committee } \\
\text { on Solar-Terrestrial Physics }\end{array}$ & S.T. Wu \\
\hline URSI & Union Radio Scientifique Internationale & J. Baldwin \\
\hline $\mathrm{CIE}$ & Compagnie Internationale de l'Eclairage & D. Crawford \\
\hline IERS (*) & International Earth Rotation Service & G. Wilkins \\
\hline
\end{tabular}

IERS subsummed BIH \& IPMS with effect from 1988 January 01, 1988. IAU Membership in ICSTI was discontinued in 1987.

\section{Financial matters}

\section{Summarized accounts}

The 3 year (1985-1987) summarized accounts are given in the following table together with the budgetary estimates. The data is extracted from the "Vérification des Comptes" for 1985, 1986 \& 1987 as certified by the IAU Auditors, R. Bâcle, HEC (1985, 1986) and P. Meyssonnier EC (1987), Paris. The unit is Swiss Francs throughout.

The ICSU mean conversion rates for Swiss Francs for 1985-1987 are:

$\begin{array}{rrrrrr} & 1 \text { US } \$ & \text { IDfl. } & \text { IFF } & \text { IDM } & \text { I Rupee } \\ 1985 & 2.4600 & 0.7423 & 0.2730 & 0.8378 & 0.2018 \\ 1986 & 1.8175 & 0.7323 & 0.2602 & & 0.1466 \\ 1987 & 1.5050 & 0.7386 & 0.2492 & & \end{array}$


TABLE I

Summary 1985-1987

Income

1. Contributions

2. Publications

3. Interest

4. UNESCO/ICSU

5. Miscellaneous

Expenditure

1. Administration

2. ICSU Contribution

3. Commission expenses

4. Commission projects

- Exchange of Astronamers

- Teaching

- Other projects

5. General Assembly

6. IAU Publications

7. Publication for Executive cormittee \& Developing Countries

8. Executive Comittee Meeting

9. Officers ting

10. Symposia \& Colloquia

11. Inter Union Comission

12. Projects of Executive Committee

13. Representation

14. Bank charges

15. International School for Young Astronamers

16. Visiting Lecturer's Programes

17. Regional Meetings

18. Special Nominating Comittee

19. Miscellaneous

Loss on transfers

\begin{tabular}{rrrrr}
\multicolumn{1}{c}{ BUDGET } & \multicolumn{1}{c}{1985} & \multicolumn{1}{c}{1986} & \multicolumn{1}{c}{1987} & \multicolumn{1}{c}{ TOTAL } \\
1244580,00 & 356459,32 & 475002,10 & 399178,41 & 1230639,83 \\
127000,00 & 12247,79 & 73235,08 & 59100,25 & 144583,12 \\
102000,00 & 47698,59 & 22688,98 & 247782,38 & 95169,95 \\
120000,00 & 68852,94 & 47358,60 & 30981,93 & 147193,47 \\
0,00 & 861,00 & 4571,98 & 1150,72 & 6583,70 \\
\hline 1593580,00 & 486119,64 & 622856,74 & 515193,69 & 1624170,07
\end{tabular}

\begin{tabular}{rrrrr}
492000,00 & 175854,45 & 196049,48 & 161138,53 & 533042,46 \\
32700,00 & 11586,60 & 6582,99 & 9833,25 & 28002,84 \\
23600,00 & & 5717,95 & 327,45 & 6045,40 \\
128000,00 & & & & \\
& 31151,54 & 18500,53 & 8327,97 & 57980,04 \\
& 23747,00 & & & 23747,00 \\
& 19819,50 & 8202,56 & 1000,00 & 29022,06 \\
213000,00 & 199633,06 & 22332,30 & 3980,00 & 225945,36 \\
50000,00 & 23722,40 & 16592,45 & 32814,48 & $731.29,33$ \\
34000,00 & 2623,47 & 7619,91 & 4526,45 & 14769,83 \\
& & & & \\
80000,00 & 1360,92 & 19564,00 & 23146,38 & 44071,30 \\
23000,00 & 3670,30 & 5274,69 & 24396,85 & 33341,84 \\
335000,00 & 96616,28 & 116160,03 & 151104,83 & 363881,14 \\
33000,00 & 13899,00 & 4816,38 & 4484,42 & 23199,80 \\
11000,00 & & & & \\
23000,00 & 8948,70 & 7904,27 & & 16852,97 \\
3500,00 & 1983,53 & 1144,71 & 3341,63 & 6469,87 \\
50000,00 & & 31543,75 & & 31543,75 \\
48000,00 & & 12784,96 & 8833,46 & 21618,42 \\
65000,00 & & 32000,00 & 16556,58 & 48556,58 \\
5000,00 & & & & \\
0,00 & 119,90 & 159,75 & & 367,84 \\
0 & & 88,19 & & \\
0,00 & 2110,68 & 512,41 & 652,02 & 3275,11 \\
\hline 1649800,00 & 616847,33 & 513551,31 & 454464,30 & 1584862,94
\end{tabular}

\section{Comments on summarized accounts}

\section{Income:}

Total income was in excess of budget.

1. Shortfall in contribution with respect to budget is largely due to late or non-payment.

4. The ICSU contribution shows a steady decline which is continuing. 


\section{Expenditure:}

1. Administrative costs were seriously underestimated in the budget. The savings in 1987 were a consequence of a change of staff and the savings of 1987 will not carry forward.

4. Commission Projects were over budget.

9. The Officers Meeting expenses were over budget in 1987 -this was a direct consequence of the staff changes.

15. There was a considerable underspend on the VLP programme.

18. 1986 includes an unsupported miscellaneous expenditure of 88.19 not detected until 1987.

\section{Balance 1985-1987}

The balance for the years $1985-1987$ is set out below:

\section{TABLE 2}

$1985 \quad 1986$

Income

Expenditure

$\mathrm{Re} /$ devaluation

Balance of the preceding year

Balance
$486119,64 \quad 622856,74$

$-616847,33-513551,29-454464,50$

$23672,68 \quad-93529,04 \quad-36317,23$

$826143,03 \quad 719088,03 \quad 735134,44$

$719088,03 \quad 735134,44 \quad 759546,40$

(*)

(*) The accounts for Symposium 130 have affected this balance as follows:

Income

Expenditure

Balance

$$
\begin{aligned}
& 55950,01 \\
& 33533,39 \\
& 22416,62
\end{aligned}
$$

Total balance as of 31.12 .87

The balance for 1987 must be increased by 22416,62 as a result of IAU Symposium 130 (income +55950.01 ; expenditure -33533.39 ) giving a reserve of 781963.02 as of 1987 December 31. The losses on valuation result from changes in major currencies -in particular the US dollar which suffered heavy devaluation during the period of accounts. The present balance is about $20 \%$ in excess of one year's working. It should be noted that ICSU is currently reviewing the balances held by member Unions.

\section{Residual budget 1988}

The residual budget for 1988 is set out in Table 3. The figures are provisional, have not been audited and do not include loss on exchange. 
TABLE 3

1. Contributions

2. Publications

\section{TABLE 3}

3. Interest

4. UNESCO/ICSU Contribution

5. Miscellaneous

\begin{tabular}{|c|c|c|}
\hline EC Budget & $\begin{array}{l}\text { Residual } \\
\text { Inc/Exp }\end{array}$ & $\begin{array}{r}\text { Difference } \\
(B-R)\end{array}$ \\
\hline 453130 & 461105 & 7975 \\
\hline 55000 & 55551 & 551 \\
\hline 35000 & 22060 & 12940 \\
\hline 35000 & 25122 & 9878 \\
\hline . & 19370 & 19370 \\
\hline 578130 & 583208 & 5078 \\
\hline
\end{tabular}

\section{Expenditure}

1. Administration

183500

11300

177719

6521

5781

2. ICSU Subvention

3. Commission expenses

4000

2702

4779

4. Commission projects

4.1. Exchange of astronomers

24000

14500

4.2. Other projects

5. General Assembly

6. IAU Publications

7. Publications for EC

240000

15000

15077

2595

337500

15662

1283

12000

8. EC Meetings

9. Officers Meetings

10. Symposia \& Colloquia

11. Inter-Union Commissions

8000

125000

9000

5000

8000

13. Representation

14. Bank charges

15.1. Young Astr. Schools

15.2. VLP

16. Regional Meetings

17. SNC

18. Miscellaneous

Total expenditure:

24000

2702

8923

11905

97500

662

Total expenditure:

Excess of expenditure over income:

684300
-106170

684397 


\section{Adopted Budget for 1989-1991}

The budget for 1989-1991 was approved at the XXth General Assembly and is given below:

TABLE 4

BUDGET (1989-1991)

All amounts in Swiss Francs

INCOME

Triennial

(1989-91)

1989

Annual

1990

1991
1.

1.1

1.2 .

1.2 .1 .

1.2 .2 .

1.2 .3$.

2.

3.

4.

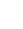

.

\section{CONTRIBUTIONS}

Adhering Organisations (238 units)

ICSU/UNESCO

ICSU Allocations

ICSU Grants

UNESCO Contracts

PUBLICATIONS

INTERESTS, etc.

OTHER RECEIPTS

\section{0}

78000

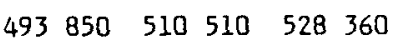

$26000 \quad 26000 \quad 26000$

$\begin{array}{lllll}165000 & 55000 & 55000 & 55000 \\ 75000 & 25000 & 25000 & 25000\end{array}$

1850720

599850

Notes:

1.1.

a. Changes of category:
- Argentina:
II to III:
now 4 units
. China:
III to $V$ :
now 10 units

b. Possibility of around 4 new Members in category I. Total: 1986-1988: 226 units 1988-1991: 238 units

c. Same inflation considered for 1989-1991 as for previous triennium; very difficult to estimate in present crisis period.

Proposed unit of contribution:

$$
\begin{aligned}
& 2075 \text { SF for } 1989 \\
& 2145 \text { SF for } 1990 \\
& 2220 \text { SF for } 1991
\end{aligned}
$$

1.2. The income from ICSU/UNESCO has decreased in the last years. It is 17335 US \$ for 1988 (in November 87 dollars !). Therefore the sum indicated in the draft can only be realistically introduced as $26000 \mathrm{SF}$.

2. 6 year contract with Reidel Publ.: same royalties as for 1986-1988 triennium. 
Triennial

(1989-91)
Annual $1989 \quad 1990$

1991

1. EXECUTIVE COMMITTEE, etc.

$\begin{array}{ll}\text { 1.1. } & \text { EC Meetings } \\ \text { 1.2. } & \text { Officers' Meetings } \\ \text { 1.3. } & \text { SNC Expenses } \\ \text { 1.4. } & \text { Other }\end{array}$

TOTAL 1.

$\begin{array}{cccc}80000 & 40000 & 40000 & - \\ 24000 & 8000 & 8000 & 8000 \\ 5000 & - & 5000 & - \\ - & - & - & - \\ 109000 & 48000 & 53000 & 8000\end{array}$

$\begin{array}{cccccc}63000 & 20000 & 21000 & 22000 \\ - & - & - & - \\ 30 & 000 & 10000 & 10000 & 10000 \\ 93000 & 30000 & 31000 & 32000\end{array}$

\section{SCIENTIFIC AND RELATED ACTIVITIES}

3.1. Meetings

3.1.1. General Assemblies

3.1.2. Symposia and Colloquia

3.1.3. Regional Astronomy Meetings

3.1.4. Young Astronomers' Schools

3.1.5. Visiting Lecturers' Programmes

3.1.6. Other

Total 3.1.

240000

365000

65000

50000

72000

792000

3.2 .

3.2.1.

3.2.2.

3.2 .2 .1 .

3.2.2.2.

3.2 .2 .3 .

3.2 .2 .4 .

3.2 .2 .5 .

3.2 .2 .6 .

Commissions Activities

Commission Expenses

Commission Projects

Exchange of Astronomers

IAU Telegram Bureau

IAU Minor Planet Center

Variable Star Catalogue

IAU Meteor Data Center

Other (incl. IERS)

Total 3.2.

15000

70000

10500

10500

10500

3000

6000

125500

Relations With Other Organisations

3.3.

3.3.1.

3.3.2.

3.3.3.

3.4.

3.4.1.

3.4.2.
Dues to ICSU

Support of Inter-Union Commissions

Representation to Other Organisations

(including liaison members)

Total 3.3.

38500

18000

24000

80500

15000

Executive Committee Projects

Other Projects

Total 3.4 .

15000

1013000

120000
32000

25000

24000

201000

5000

23000

3500

3500

3500

1000

2000

41500

$120^{\circ} 000$

33000

25000

24000

24000

$202000 \quad 389000$

$5000 \quad 5000$

$23000 \quad 24000$

3500

3500

3500

3500

$3500 \quad 3500$

1000

1000

2000

2000

41500

42500

12500

6000

12800

13200

8000

6000

6000

8000

8000

$26500 \quad 26800$

27200

$$
5000 \quad 5000 \quad 5000
$$

$5000 \quad 5000 \quad 5000$

TOTAL 3. 
4.

4.1. Secretariat

4.1.1.

4.1.2.

4.1.2.1.

4.1.2.2.

4.1.2.3.

4.1.2.4.

4.1.3.

4.1.3.1.

4.1.3.2.

4.1.4.

4.1.5.

4.2.

4.2.1.

4.2.2.

4.2.3.

4.2.4.

Total 4.I.

Other
Salaries and Social Charges, etc.

Office Expenses

Rent, Heating, Light, Cleaning, etc.

Communication (PTT)

Equipment (Major)

Office Supplies

General Secretary's Expenses

Travel, Subsistence

Representation

President's Expenses

Ass. General Secretary's Expenses +

Local help (AGS)

Bank Charges

Audit Fees, Legal Advice

Loss on Exchange

Miscellaneous

Total 4.2.

TOTAL 4.

TOTAL EXPENDITURE

INCOME - EXPENDITURE

$\begin{array}{rrrr}375000 & 120000 & 125000 & 130000 \\ 165000 & 50000 & 55000 & 60000 \\ & & & \\ & & & \\ 57000 & 18000 & 19000 & 20000 \\ & & & \\ 18000 & 6000 & 6000 & 6000 \\ 12000 & 4000 & 4000 & 4000 \\ 3000 & 1000 & 1000 & 1000 \\ 630000 & 199000 & 210000 & 221000\end{array}$

$\begin{array}{rccc}3000 & 1000 & 1000 & 1000 \\ 4500 & 1500 & 1500 & 1500 \\ - & - & - & - \\ - & - & - & - \\ 7500 & 2500 & 2500 & 2500 \\ 637500 & 201500 & 212500 & 223500\end{array}$

$1852500 \quad 553500 \quad 571800 \quad 727200$

$-1780+46350+44710-92840$

Notes:

1.1. EC meetings: less expensive than expected during 1986-1988, because of locations and absences at EC 56.

For future: include President-Elect.

2.1. Mailing of Information Bulletin had been underestimated for previous triennium; one has also to take into account hundreds of new members after the $X X$ th General Assembly.

3. No major change foreseen for next triennium.

4.1. Secretariat

4.1.1. Salaries: had been strongly underestimated for 1986-88 triennium; however, because of new personnel (i.e. one full-time administrative assistant, and one part-time (2/3) bilingual secretary), costs will not increase much during 19891991.

4.1.2. The location of the Paris secretariat may change in 1988, so that an estimate of the expenses is hard to make. A very slight increase over the figure of the previous triennium was made.

4.1.3. G.S. expenses: here also, underestimated for 1986-88.

4.1.4. President's expenses: one has to include trips for useful contacts in several countries: increase this item. 


\section{List of Adhering Organizations}

(Not reproduced here, see Chapter VII).

\section{List of deceased Members}

(See updated list on pp. 25-26).

\section{List of IAU publications}

\section{Transactions and Highlights}

Transactions XIXA: (Delhi, 1985) pp. viii + 736, D. Reidel Publ. Co., 1985

Transactions XIXB: (Delhi, 1985) pp. xii + 656, D. Reidel Publ. Co., 1986

Transactions XXA: (Baltimore, 1988) pp. viii + 708, Kluwer Academic Publ., 1988

Highlights of Astronomy, 7, as presented at the XIXth General Assembly of the IAU, 1985, pp. xvi + 900, D. Reidel Publ. Co., 1986

IAU Symposia Volumes (edited by Reidel Publ. Co. \& by Kluwer Academic Publ.)

106 The Milky Way Galaxy

H. van Woerden, R.D.J. Allen \& W.B. Burton, pp. xxiv + 660, 1985

109 Astrometric Techniques

H.K. Eichhorn \& R.J. Leacock, pp. xxi + 838, 1986

111 Calibration of Fundamental Stellar Quantities

D.S. Hayes et al., pp. xxiv + 646, 1985

112 The Search for Extraterrestrial Life: Recent Developments M. Papagiannis, pp. xxvi $+580,1985$

113 Dynamics of Star Clusters

J. Goodman \& P. Hut, 644 p., 1985

114 Relativity in Celestial Mechanics and Astrometry, High Precision Dynamical Theories and Observational Verifications

J. Kovalevsky \& V.A. Brumberg, pp. xvii + 426, 1986

115 Star Forming Regions

M. Peimbert \& J. Jugaku, pp. xxxiv $+734,1985$

116 Luminous Stars and Associations in Galaxies

C.W.H. de Loore, A.J. Willis \& P. Laskarides, pp. $x x+530,1986$

117 Dark Matter in the Universe

J. Kormendy \& G.R. Knapp, pp. xxix + 596, 1986

118 Instrumentation and Research Programs for Small Telescopes P.L. Cottrell \& J.B. Hearnshaw, pp. xxii $+482,1986$

119 Quasars

G. Swarup \& V.K. Kapahi, pp. xxii $+606,1986$ 
120 Astrochemistry

M.S. Vardya \& S.P. Tarafdar, pp. xxviii + 640, 1986

121 Observational Evidence of Activity in Galaxies

E. Ye Khachikian, K.J. Fricke \& J. Melnick, pp. xxii + 601, 1987

122 Circumstellar Matter

I. Appenzeller \& C. Jordan, pp. xxiv $+607,1987$

123 Advances in Helio- and Astroseismology

J. Christensen-Dalsgaard \& S. Frandsen, pp. xxi $+604,1988$

124 Observational Cosmology

A. Hewitt, G. Burbidge \& Li Zhi-Fang, pp. xxiii $+854,1987$

125 The Origin and Evolution of Neutron Stars

D.J. Helfand \& J.-H. Huang, pp. $x x+572,1987$

126 Globular Cluster Systems in Galaxies

J.E. Grindlay \& A.G. Davis Philip, pp. xxviit 750, 1987

127 Structure and Dynamics of Elliptical Galaxies

T. de Zeeuw, pp. xxv + 579, 1987

128 The Earth's Rotation and Reference Frames for Geodesy

A.K. Babcock \& G.A. Wilkins, pp. xviii + 470, 1988

129 The Impact of VLBI on Astrophysics and Geophysics

M.J. Reid \& J.M. Moran, pp. xxiv + 599, 1988

132 The Impact of Very High S/N Spectroscopy on Stellar Physics

G. Cayrel de Strobel \& M. Spite, pp. xxxiii + 626, 1988

\section{IAU Colloquia Volumes}

81 Local Interstellar Medium

Y. Kondo, F.C. Bruhweiler \& B.D. Savage, NASA Conference Publication 2345, 356 p., 1984

82 Cepheids, Theory and Observations

B.F. Madore, Cambridge University Press, pp. ix + 300, 1985

83 Dynamics of Comets: Their Origin and Evolution

A. Carusi \& G.B. Valsecchi, D. Reidel Publ. Co., pp. xii + 400, 1985

84 Longitude Zero Symposium 1884-1984

S.R. Malin, A.E. Roy \& P. Beer, Pergamon Press, in the series Vistas in Astronomy, 28, parts l/2, 407 p., 1985

85 Properties and Interactions of Interplanetary Dust

R.H. Giese \& P. Lamy, D. Reidel Publ. Co., pp. xxxvi + 444, 1985

86 Eighth International Colloquium on Ultraviolet and $X$-ray Spectroscopy of Astrophysical Laboratory Plasmas

G.A. Doschek, published by the Naval Research Laboratory, 1986 
87 Hydrogen Deficient Stars and Related Objects H. Hunger, D. Schönberner \& N. Kameswara Rao, D. Reidel Publ. Co,. in the series Astrophysics and Space Science Library 128, pp. $x x+506,1986$

88 Stellar Radial Velocities

A.G. Davis Philip \& D.W. Latham, L. Davis Press, pp. xi $+455,1985$

89 Radiation Hydrodynamics in Stars and Compact Objects

D. Mihalas \& K.-H.A. Winkler, Springer-Verlag in the series Lecture Notes in Physics, 255, pp. ix $+454,1986$

90 Upper Main Sequence Stars with Anomalous Abundances

C.R. Cowley, M.M. Dworetsky \& C. Mégessier, D. Reidel Publ. Co., in the series Astrophysics and Space Science Library, 125, pp. xiv + 489, 1986

91 History of Oriental Astronomy

G. Swarup, Cambridge University Press, pp. xiv $+289,1987$

92 Physics of Be Stars

A. Slettebak \& T.P. Snow, Cambridge University Press, pp. xvii + 557, 1987

93 Cataclysmic Variables

H. Drechsel, J. Rahe \& Y. Kondo, D. Reidel Publ. Co., reprinted from Astrophysics and Space Science, $130 n^{\circ} 1 \& 2,131, n^{\circ} 1 \& 2,1987$

94 Physics of Formation of Fell Lines Outside LTE

R. Viotti, A. Vittone \& M. Friedjung, D. Reidel Publ. Co., in the series Astrophysics and Space Science Library, 138, 1988

95 The Second Conference on Faint Blue Stars

A.G. Davis Philip, D.S. Hayes \& J.W. Liebert, L. Davis Press, Inc., pp. xxix + 778, 1987

96 The Few Body Problem

M.J. Valtonen, D. Reidel Publ. Co., 1988

97 Wide Components in Double and Multiple Stars

J. Dommanget, E.L. van Dessel \& Z. Kopal, D. Reidel Publ. Co., reprinted from Astrophysics and Space Science, 142, 1988

98 Stargazers, The Contribution of Amateurs to Astronomy

S. Dunlop \& M. Gerbaldi, Springer-Verlag, pp. xvii $+237,1988$

$\&$

La contribution des Astronomes Amateurs à l'astronomie

Observations \& Travaux, Hors série $N^{0} 1,2,3 \& 4$

Société Astronomique de France

99 Bioastronomy, Next Steps

G. Marx, D. Reidel Publ. Co., 1988

101 Supernova Remnants and the Interstellar Medium

R.S. Roger \& T.L. Landecker, Cambridge University Press, pp. xi + 540, 1988

102 UV and X-ray Spectroscopy of Astrophysical and Laboratory Plasmas

F. Bely-Dubau \& P. Faucher, Journal de Physique, 49, pp. xvii $+400,1988$

103 The Symbiotic Phenomenon

J. Mikolajewska, M. Friedjung, S.J. Kenyon \& R. Viotti, eds., Kluwer Academic

Publishers, in the Series Astrophysics and Space Science Library, 145, pp. xvi $+365,1988$ 


\section{Proceedings of Regional Astronomy Meetings}

Seventh European

Florence, Italy, December 12-16, 1983

Frontiers of Astronomy \& Astrophysics

R. Pallavicini, Italian Astronomical Society, Florence, Italy

Eighth European

Toulouse, France, September 17-21, 1984

New Aspects of Galaxy Photometry

J.-L. Nieto, Springer-Verlag in the series Lecture Notes in Physics, 232, 350 p., 1985

High Resolution in Solar Physics

R. Muller, Springer-Verlag in the series Lecture Notes in Physics, 233, 320 p., 1985

Nearby Molecular Clouds

G. Serra, Springer-Verlag in the series Lecture Notes in Physics, 237, 242 p., 1985

Third Asian-Pacific

Kyoto, Japan, September 30-October 5, 1984

Ed. M. Kitamura \& E. Budding, D. Reidel Publ. Co, part I: 552 p.; part II: 264 p., 1986

Fourth Latin-American

Rio de Janeiro, Brazil, November 18-23, 1984

Ed. P. Pismis \& S. Torres-Peimbert, special issue of Revista Mexicana de

Astronomia y Astrofisica, 12, 452 p., February 1986

Fourth Asian-Pacific

Beijing, China, PR, October 5-9, 1987

Vistas in Astronomy, 31, 1988, Science Press (Pergamon Press), Beijing

\section{Miscellaneous Publications}

Image Detection and Quality

SFO \& ANRT meeting, co-sponsored by the IAU, SPIE, eds., 1987

\section{Commission Publications}

Commission 10: Quarterly Bulletin on Solar Activity.

Published at the Tokyo Astronomical Observatory, F. Moriyama, Mitaka, Takyo 181, Japan.

Commission 10: Sunspot Bulletin.

Published by the Sunspot Index Data Center (SIDC), Dr. A. Koeckelenbergh, 3 Avenue Circulaire, B-1180 Bruxelles, Belgium.

Commission 19: Circulaires du Bureau International de I'Heure.

A monthly publication of Bureau International de l'Heure, 6l, Avenue de l'Observatoire, 75014 Paris, France (now terminated).

Cornmission 19: Monthly Notes of the International Polar Motion Service.

Prepared and distributed by the Central Bureau of the International Polar Motion Service, International Latitude Observatory of Mizusawashi, Iwate-ken, Japan. 
Commission 20: Minor Planet Circulars.

Issued by the Minor Planet Center, B.G. Marsden, Center for Astrophysics, 60 Garden Street, Cambridge, MA 02138, USA

Commission 27: Information Bulletin on Variable Stars.

Prepared and distributed by the Konkoly Observatory of the Hungarian Academy of Sciences , 1525 Budapest XII, Box 67, Hungary.

Commission 27: Catalogue of Variable Stars

Catalogue of Suspected Variable Stars.

Name-lists of Variable Stars.

Distributed by Publishing House Nauka, Moscow, USSR

Commission 29: Nucleosynthesis in the Galaxy from the Study of Low-Mass Stars

Proceedings ot the IAU Commission 29 Meeting, held in New-Delhi, India, 1985

G. Cayrel de Strobel \& M. Parthasarathy, Eds., Journal of Astrophysics \& Astronomy, 8, No. 2, 1987

Commission 46: Newsletter on the Teaching of Astronomy.

Commission 46: Astronomy Education Materials. 